\title{
Formulating Monoclonal Antibodies as Powders for Reconstitution at High Concentration using Spray Drying: Models and Pitfalls
}

\author{
Maarten Batens ${ }^{\mathrm{a}, *}$, Jan Massant ${ }^{\mathrm{b}}$, Bianca Teodorescu ${ }^{\mathrm{c}}$, \\ Guy Van den Mooter ${ }^{a, * *}$ \\ ${ }^{a}$ Drug Delivery and Disposition, KU Leuven, Leuven, Belgium \\ ${ }^{b}$ Biological Formulation Development, UCB Pharma, Braine l'Alleud, Belgium \\ ${ }^{c}$ Non-Clinical Statistics, UCB Pharma, Braine l'Alleud, Belgium
}

\begin{abstract}
In anticipation of non-invasive routes capable of delivering adequately high, systemic monoclonal antibody (mAb) concentrations, subcutaneous (SC) injection is arguably the most patient friendly alternative administration route available for this drug class. However, due to the limited volume that can be administered through this route and mAbs' relatively low therapeutic activity, solutions for subcutaneous injection often need to be highly concentrated, making them inherently more prone to potentially detrimental protein (self-)interaction, which is why mAb formulations for SC injection and other highly concentrated mAb solutions are often dried to increase their stability. In this work we investigated spray drying (SD) as an drying technique for formulating mAbs as powders for reconstitution, assessing the influence of SD process parameters, as well as excipients present in the feed solution on both mAb stability and relevant powder characteristics for reconstitution using a model mAb. By employing a design of experiments approach we were able to provide statistically substantiated evidence for the reconstitution time reducing and stability improving properties of L-arginineHCl, L-histidineHCl, and L-lysine $\mathrm{HCl}$ and polysorbate 20 when combined with a disaccharide in
\end{abstract}

\footnotetext{
*ORCiD: 0000-0003-4245-0782

** Corresponding author at Department of Pharmaceutical and Pharmacological Sciences, Drug Delivery and Disposition, KU Leuven - University of Leuven O\&N2, Herestraat 49 Bus 921, 3000 Leuven, Belgium.

Email address: guy.vandenmooter@kuleuven.be (Guy Van den Mooter )
} 
SD mAb powders for reconstitution. Additionally, the study yielded several statistical models describing process parameter influences on relevant powder and $\mathrm{mAb}$ stability characteristics.

Keywords: Monoclonal antibody, High concentration, Reconstitution, Spray drying, Protein formulation, Stability, Amino acid, Disaccharide, Surfactant, Design of experiments

\section{Introduction}

Oral, pulmonary, intranasal, transdermal and other non-invasive administration routes are being actively investigated for the delivery of monoclonal antibodies (mAbs), but none of these routes are currently able to yield systemic concentrations high enough to make them feasible for monoclonal antibody therapy, currently making liquid injections, i.e. intravenous (IV), intramuscular (IM) or subcutaneous (SC) injection, the only feasible options for mAb administration (Wan et al. (2012); Roberts (2014); Moroz et al. (2016)). $\mathrm{SC}$ injection is the preferred route out of aforementioned options as it allows self-administration by the patient, potentially limiting the impact on the patient's daily life and overall treatment cost (Kinnunen and Mrsny (2014)). However, the volume that can be administered via this route, in absence of specialised devices or enzymatic methods like hyaluronidase-facilitated subcutaneous infusion systems, is very limited $(1.5-2 \mathrm{ml})$, making it necessary to administer highly concentrated mAb formulations $(\geq 100 \mathrm{mg} / \mathrm{mL})$ (Wasserman et al. (2012); Roberts (2014)). Consequently, the higher mAb concentration in these liquid formulations will increase the chances of protein self-interaction, thus elevating the risk of irreversible aggregation, which is associated with a decrease in product efficacy and an increased risk of immunogenic responses (Roberts (2014); Barnett et al. (2015); Mahler et al. $(2009))$.

Therefore, $\mathrm{mAb}$ formulations for $\mathrm{SC}$ injection and other highly concentrated $\mathrm{mAb}$ solutions are often dried when their liquid form is insufficiently stable, as the removal of water drastically reduces protein conformational mobility and limits the transport of small-molecule reactants, subsequently reducing the rate of protein self-interaction and degradation mechanisms, thus improving the formulation's (storage) stability (Cicerone and Douglas (2012)). Different mechanisms and models for protein stabilisation in liquid state, during drying and in solid state have been proposed over the years. 
The interested reader is referred to some excellent reviews treating this topic Ohtake et al. (2011), Kamerzell et al. (2011), Balcão and Vila (2015) and Cicerone et al. (2015).

The drying of protein formulations is often done by lyophilisation, as there is no risk of exposing the proteins to high temperatures. However, a major downside to lyophilisation is the amount of stress generated both during the freezing and drying phases, potentially resulting in a partial or complete loss of activity. Even though the stress during lyophilisation is nowadays well controlled by addition of protein protective excipients, lyophilisation still remains relatively highly time and energy consuming. Alternatively, protein formulations can be dried using spray drying, which is a fast, one-step process yielding powders of which properties like morphology, density and powder flow can be optimised by altering either the spray drying process or the $\mathrm{mAb}$ formulation. Although spray drying uses relatively high temperatures, the heat exposure of the protein is minimal, i.e. as long as there is adequate solvent evaporation, the droplet surface and thus the protein, will maintain at the wet-bulb temperature, being significantly lower than the temperature of the hot drying gas, and due to the overall short duration of the spray drying process (Ameri and Maa (2006)). To reduce the impact of stress factors like shear stress, exposure to air/liquid interfaces or increased heat stress upon loss of hydration shell and to further increase solid state stability, suitable excipients are added, many of which having been reported to also stabilise proteins during lyophilisation (Ameri and Maa (2006); Ajmera and Scherließ (2014)). Among these are disaccharides, e.g. trehalose, which have been reported to stabilise proteins during lyophilisation and in solid state, some amino acids, e.g. L-arginine, that have been attributed protein stabilising properties in liquid and solid state and certain non-ionic surfactants like polysorbates and poloxamers, which have been reported to prevent interfacial-induced protein denaturation (Kamerzell et al. (2011); Cao et al. (2013); Ajmera and Scherließ (2014); Wang et al. (2017)). Even though considerable research has been devoted to determine the influence of these excipients on protein stability, the majority has focused on liquid formulations, lyophilisation or spray drying for inhalation, rather than on powders for reconstitution at high mAb concentrations. Furthermore, little research is available concerning relevant formulation, powder and process characteristics for this class of drug products.

The novelty of this study was therefore twofold: First; to determine the impact of adding a non-ionic surfactant, polysorbate 20, and hydrochloride 
salts of the three basic amino acids, L-histidine, L-arginine and L-lysine, in the presence of a disaccharide, being either trehalose or sucrose on mAb stability during the drying process and subsequent storage, as well as on relevant characteristics for reconstitution at high mAb concentrations. Polysorbate 20 was selected as a surfactant based on previous reports stating polysorbate 20 , as well as polysorbate 80 , possessing protein protective properties in both liquid formulations as during (freeze) drying. In addition, polysorbate 20 and 80 are also two of the most commonly used non-ionic surfactants in protein formulations (Kamerzell et al. (2011)). The choice for basic amino acids was based on a preliminary screening study (data not included) performed to reduce the number of factors in the subsequent formulation screening design which included fifteen amino acids: L-alanine, L-arginine, L-cysteine, L-glutamic acid, L-glutamine, L-glycine, L-histidine, L-isoleucine, L-leucine, L-lysine, L-phenylalanine, L-proline, L-serine, L-tryptophan and L-valine or their respective hydrochloride salts of which the mAb stabilising properties in absence of a sugar stabiliser were assessed. The aforementioned preliminary screening study also revealed that amino acids or their respective salts insufficiently stabilised the model mAb in solid state, necessitating the addition of a glassy sugar matrix. Trehalose and sucrose were selected as glassy matrix formers due to their demonstrated protein stabilising properties in naturally occurring organisms, for instance during anhydrobiosis of certain organisms, as well as in (freeze) dried pharmaceutical formulations (Cordone et al. (2015); Malferrari et al. (2016); Mensink et al. (2017)). Despite being homologous disaccharides, trehalose and sucrose have been reported to display differences in their protein stabilising efficiencies, with the bioprotective properties of sucrose being dependent on the sugar/protein ratio, which has to be sufficiently low for stabilisation, while protein stabilisation by trehalose is stated to be independent of the protein concentration (Malferrari et al. (2016); Mensink et al. (2017)). Sucrose was therefore included in the presented study, as our focus was on highly concentrated mAb solutions, which included relatively low sugar/protein ratios, and sucrose could prove to be a cost effective alternative to trehalose. In this respect it should also be mentioned that not only the choice of sugar, but also method of drying will determine how well a protein will be stabilised (Cordone et al. (2015); Mensink et al. (2017)). The attentive reader may have also noticed the omission of other homologous disaccharides commonly used in pharmaceutical practice such as maltose or lactose form the presented study. This was done deliberately as, contrary to trehalose and sucrose, the aforementioned 
disaccharides are reducing sugars which, in combination with a protein, enable chemical degradation in the form of Maillard browning (Mensink et al. (2017)). The second novelty of this study was to determine the impact of spray drying process parameters on both the powder characteristics relevant for reconstitution at high $\mathrm{mAb}$ concentrations and on stability of the mAb during the drying process and subsequent storage. In order to achieve these objectives, a design of experiments approach was used which combined statistical tools with a number of orthogonal analytical techniques.

\section{Materials}

A Humanised IgG4 monoclonal antibody was provided by UCB Pharma (Braine l'Alleud, Belgium). The sodium hydroxide stock solution, L-histidine monohydrochloride monohydrate and polysorbate 20 were obtained from Merck (Darmstadt, Germany). L-arginine monohydrochloride, L-lysine monohydrochloride and $\mathrm{D}(+)$-trehalose dihydrate were obtained from Sigma-Aldrich (St. Louis, Missouri, U.S.). D(+)-Sucrose was purchased from Applichem (Darmstadt, Germany). L-histidine was purchased from Merck and SigmaAldrich for the formulation and spray drying (SD) process parameter screening formulations, respectively. Lactic acid and hydrochloric acid stock solutions were provided by Fisher scientific (Pittsburgh, Pennsylvania, U.S.).

\section{Methods}

\subsection{Manufacturing process}

\subsubsection{Preparation of feed solutions}

Tangential flow diafiltration was used to exchange the mAb's storage buffer with an aqueous stock solution ( $\mathrm{pH}$ 5.0) containing either a sugar $(0.1 \mathrm{M})$ and lactate $(0.05 \mathrm{M})$, or L-arginineHCl $(0.24 \mathrm{M})$, trehalose $(0.1 \mathrm{M})$ and L-histidine $(0.05 \mathrm{M})$. After the diafiltration step, the solutions were further concentrated and filtered (Polyethersulfone, $0.22 \mu \mathrm{m}$, Merck Millipore, Bedford Massachusetts, U.S.). The concentration of the mAb solutions was measured using UV absorbance at $280 \mathrm{~nm}$ with extinction coefficient $1.33(\mathrm{mg} / \mathrm{ml})^{-1} . \mathrm{cm}^{-1}$, and adjusted to $100 \mathrm{mg} / \mathrm{ml}$. Feed solutions used during the formulation screening (see 3.2.1) were prepared by adding filtered $(0.22 \mu \mathrm{m})$ solutions of the remaining excipients. Solutions used during the SD process parameter screening experiments (see 3.2.2), were spiked with an equivalent of $4 \cdot 10^{-6} \mathrm{~mol}$ polysorbate 20 per $\mathrm{g}$ mAb present in the solution 
and diluted with ultra pure water (Type $1\left(\rho \geq 18.2 \mathrm{M} \Omega . \mathrm{cm}\right.$ at $\left.25{ }^{\circ} \mathrm{C}\right)$ and filtered $(0.22 \mu \mathrm{m}))$ to their final concentrations.

\subsubsection{Spray drying (SD)}

Feed solutions for the formulation screening experiments were spray dried at an $\mathrm{mAb}$ concentration of $50 \mathrm{mg} / \mathrm{ml}$ and a total feed volume of $15 \mathrm{ml}$, using a Büchi B-290 Mini Spray Dryer, equipped with a $0.7 \mathrm{~mm}$ two-fluid nozzle, high performance cyclone, small collection vessel and the B-296 Dehumidifier (Büchi Labortechnik AG ,Flawil, Switzerland). Settings were based on inhouse procedure and kept constant for all formulation screening experiments. Inlet air temperature was set at $120{ }^{\circ} \mathrm{C}$ (outlet temperature was monitored and ranged between $55-60{ }^{\circ} \mathrm{C}$ ), inlet air flow rate at $580 \mathrm{l} / \mathrm{min}$, nozzle $\mathrm{N}_{2}$ flow rate at $10 \mathrm{l} / \mathrm{min}$ and the solution feed rate was set at $3 \mathrm{ml} / \mathrm{min}$.

A ProCepT Micro-Spray was used for the SD process parameter screening study. The Micro-Spray was equipped with a Bi-fluid Micro nozzle with interchangeable nozzle tips, a single cylindrical process column connected to the glass cone (together referred to as the drying chamber), connected to the medium cyclone with small collection vessel via the glass cooling tube and transport tube, all supplied by ProCepT nv (Zelzate, Belgium). Compressed air was used for atomisation and HEPA filtered air as the drying gas.

Following the process, yields were calculated based on the quantity of powder in the collection vessel, corrected for residual water content (see 3.2.4). The powder from the collection vessel (collector) was then pooled with the powder recovered from the cyclone and dispensed into $2 \mathrm{ml}$ Type I, clear, tubular glass injection vials (Schott AG, Mainz, Germany) closed with FluroTec ${ }^{\circledR}$ rubber injection stoppers (West pharmaceutical services, West Whiteland Township, Pennsylvania, U.S.) and aluminium crimp seals (Adelphi healthcare packaging, West Sussex, U.K.). Sample handling was performed under ambient conditions, with ambient conditions defined as a climate controlled lab in case of the formulation screening study and a lab without climate control, but where temperature and relative humidity were actively monitored, in case of the process parameter screening study. For the process parameter screening study, logged relative humidity and temperature data were plotted against all responses and did not reveal any obvious trends or correlations between the monitored environmental conditions and the responses of the design. Finally, samples were stored either at $5{ }^{\circ} \mathrm{C}$ or at $40{ }^{\circ} \mathrm{C}$ during 4 weeks, followed by storage at $5{ }^{\circ} \mathrm{C}$ prior to analysis. The powder recovered from the ProCepT Micro-Spray's transport tube was collected in 
a separate vessel and stored at $5{ }^{\circ} \mathrm{C}$ prior to laser diffraction analysis. The separation of the transport tube powder fraction from the collector/cyclone fraction was performed based on previous work by Worku et al. (2014), showing different solid state properties of the material collected in the transport tube. Characterisation was performed on the collector/cyclone powder fraction, unless explicitly specified.

\subsection{Design of experiments (DoE)}

\subsubsection{Formulation screening design}

Table A.1 summarises the factors and factor levels investigated by the full factorial design depicted in Table A.2. Runs were carried out in a randomised sequence, generated by the JMP Genomics 8 software package (SAS Institute, Cary, North Carolina, U.S.).

\subsubsection{SD process parameter screening design}

Table A.3 summarises the factors and factor levels used in the D-optimal design used for SD process parameter screening (Table A.4). The experiments were designed to avoid confounding between main effects, between two-factor interactions or between main effects and two-factor interactions. Two-factor interactions are still confounded with three-factor interactions, but these were assumed te be negligible.

\subsubsection{Statistical analysis}

All statistical analysis was performed using the JMP software package. Models were fitted using the standard least squares method. For the SD process parameter screening design, the fitting step was preceded by a stepwise regression procedure to reduce the number of terms in the model with $p$-value thresholds $(\leq 0.05$ to enter during a forward step and $\geq 0.1$ to leave during a backward step), applying the "combine" rule, which combined an interaction term with its constituent terms and calculated the significance probability for entry of the resulting combination term using a joint F-test. The stepwise regression procedure was run in the "mixed" direction, alternating forward and backward steps, including the most significant term with a $p$-value $\leq 0.05$ and removing the least significant term with a $p$-value $\geq$ 0.1 , respectively. At each iteration terms were removed until all remaining terms were significant, after which the process proceeded in the "forward" direction until all terms meeting the entering criterion ( $p$-value $\leq 0.05)$ were included. The validity of the resulting models was verified by checking the 
normality of the studentised residuals' distributions using a Shapiro-Wilk test for normality as a measure for the goodness of fit.

Potential outliers were identified, using Mahalanobis and jackknife distances in the multivariate sense, which included all continuous factors and the response in question (Penny (1996)). The tests were performed at an $\alpha$-level of 0.05 , followed by analysis of the Cooks distances of each point in the model to evaluate the influence of each data point on the fit (Altman and Krzywinski (2016)). No outliers were omitted from the models unless explicitly specified.

\subsubsection{Karl Fischer titration (KF)}

The residual water content of the spray dried powders was determined using a $831 \mathrm{KF}$ Coulometer with generator electrode (without diaphragm), coupled to a 774 Oven Sample Processor (Metrohm AG (Herisau, Switzerland). Samples (20-30 mg) were heated to $120{ }^{\circ} \mathrm{C}$ in $6 \mathrm{ml}$ clear glass head space vials, which were closed using septum seals with PTFE inserts (Metrohm). Water contents are expressed as mass percentages unless otherwise specified.

\subsubsection{Angle of repose (AoR)}

Powder flow was expressed using the angle of repose. The method was based on the European Pharmacopoeia (8th edition, chapter 2.9.36) and consisted of pouring $200 \mathrm{mg} \pm 7 \mathrm{mg}$ of powder through a glass funnel (inner stem diameter $3.50 \mathrm{~mm}$, outer stem diameter $6.09 \mathrm{~mm}$, total funnel height $62.84 \mathrm{~mm}$ ) onto a glass surface positioned $20.00 \mathrm{~mm}$ lower (distance between the funnel tip and the glass surface). The smallest and largest diameters of the resulting powder cone base were measured and averaged, since the base was never perfectly circular. The resulting cone base diameter and cone height were then used to calculate the angle of repose $(\alpha)$ with equation 1.

$$
\alpha=\arctan \left(\frac{\text { Cone height }}{0.5 \cdot \text { Cone base diameter }}\right)
$$

\subsubsection{Laser diffraction (LD)}

Particle size distributions of the different powders were measured using a Mastersizer 2000 particle size analyser equipped with a Hydro 2000S dispersion unit (Malvern Instruments Ltd, Worcestershire, U.K.). Propan-2-ol was used as a dispersant (refractive index 1.39), due to the formulations' insolubility in this medium. Stirrer speed was set at $2100 \mathrm{rpm}$, obscuration 
limits were set to 5 and $15 \%$ and refractive index and absorption of the samples were fixed at 1.6 and 0.01 , respectively. The general purpose model with enhanced sensitivity was selected in the Mastersizer 2000 software (version 5.61) since particle size distribution and morphological properties of the powders were unknown prior to analysis. After dispersion, samples were subjected to 30 seconds of ultrasonication to break up larger agglomerates into their primary particles. A $512 \mu \mathrm{m}$ cut-off was applied when ultrasonication was unable to break up a small agglomerate fraction, resulting in a clear bimodal distribution (visible as an aggressive fluctuation in the signal). After ultrasonication, a delay was applied of at least 150 seconds or until a stable signal was obtained, whichever lasted longer, before starting the measurements $(\mathrm{n}=3,20000$ snaps/measurement). For this work, the following variables were determined to describe the particle size distributions:

- $\mathrm{d}(0.10), \mathrm{d}(0.50)$ and $\mathrm{d}(0.90)$, being the $10^{\text {th }}, 50^{\text {th }}$ and $90^{\text {th }}$ percentiles of the cumulative volume distribution, respectively.

- $\mathrm{D}[3,2]$, surface weighted mean or Sauter mean diameter, which is correlated to the specific surface area, was calculated using equation 2.

$$
D[3,2]=\frac{\sum d^{3}}{\sum d^{2}}
$$

- $\mathrm{D}[4,3]$, volume weighted mean or De Brouckere mean diameter, which reflects the size of those particles constituting the bulk volume of the sample, was calculated using equation 3.

$$
D[4,3]=\frac{\sum d^{4}}{\sum d^{3}}
$$

- Span, a descriptor for unimodal distributions, was calculated using equation 4.

$$
\operatorname{Span}=\frac{d(0.10)-d(0.90)}{d(0.50)}
$$

- Uniformity, a measure for the absolute deviation from the median $(\mathrm{d}(0.50))$, was calculated using equation 5 . 


$$
\text { Uniformity }=\frac{\sum V_{i}\left|d(0.50)-d_{i}\right|}{\sum V_{i}|d(0.50)|}
$$

With $d_{i}$ and $V_{i}$ being the mean diameter and relative volume in size class i, respectively.

\subsubsection{Powder reconstitution time}

Samples were reconstituted at $100 \mathrm{mg} / \mathrm{ml}$ by injecting a calculated volume of ultra pure water through the closed vials' septa using a syringe and 21 gauge needle. After water addition, the vial was gently swirled to evenly distribute the solvent. Aside from the initial, gentle swirl samples were neither shaken nor agitated in any way during the process. Reconstitution time measurement was started when the first water droplet left the needle and continued until a clear, homogeneous solution or, when insoluble particles were present, a homogeneous dispersion was obtained. Only the bulk reconstitution time was taken into account. The latter being defined as the time needed for the majority of powder to go into solution with the exception of a few adhering lumps, as these lumps were causing an non-reproducible increase in reconstitution time. Due to the observational nature of this method, the use of different analysts was reported to be a main source of variability by Cao et al. (2013). Therefore, all sample reconstitution and reconstitution time measurement was done by the same analyst.

\subsubsection{Size-exclusion chromatography (SEC)}

Size-exclusion chromatography (SEC) was used to relatively quantify multimeric/high molecular weight ( $\mathrm{Mw}$ ) species (i.e. dimers, trimers, tetramers, ...) in the reconstituted samples as a measure for the loss of monomeric mAb. Analysis was performed using an Infinity 1260 high performance liquid chromatography (HPLC) system (Agilent Technologies, Was-bronn, Germany) equipped with a TSK-GEL G3000SW ${ }_{X L}$ column $(5 \mu \mathrm{m}, 300 \mathrm{~mm} \times 7.8 \mathrm{~mm})$ (Tosoh Biosciences, Germany) and UV-detector (set at 280nm). A filtered $0.1 \mathrm{M}$ sodium phosphate solution containing $0.3 \mathrm{M} \mathrm{NaCl}(\mathrm{pH} 7.0)$, was used as the mobile phase. Samples were diluted to $5 \mathrm{mg} / \mathrm{ml}$ using mobile phase and $50 \mu \mathrm{l}$ was injected. The process was run isocratically at ambient temperature, for 15 minutes with a flow rate of $1 \mathrm{ml} / \mathrm{min}$. Peak integration was performed using the Empower (version 3) ApexTrack ${ }^{\circledR}$ algorithm (Waters Corporation, Milford, Massachusetts, U.S.). 


\subsubsection{Dynamic light scattering (DLS)}

A Wyatt Möbiu $\zeta$ Zeta Potential and DLS detector (Wyatt, Santa Barbara, California, U.S.) was used to quantify the fraction of high $\mathrm{Mw}$ aggregates (diameter range 1-2 $\mathrm{nm}$ to $3-5 \mu \mathrm{m}$ ) present in the reconstituted samples, as these would be otherwise overlooked due the upper size limit inherent to SEC (den Engelsman et al. (2010)). The laser wavelength was $532 \mathrm{~nm}$, detector angle $163.5^{\circ}$ and samples were diluted to $10 \mathrm{mg} / \mathrm{ml}$ with a pH 5.0, $0.05 \mathrm{M}$ lactate (formulation screening samples) or L-histidine (SD process parameter screening samples) solution, prior to the measurement. Data was recorded at $25.0{ }^{\circ} \mathrm{C}$, using auto-attenuation and peak radius cutoffs set at 0.500-2.500 and 2.000-2000.0000 $\mathrm{nm}$ for the formulation and SD parameter screening experiments, respectively. The number of acquisitions and acquisition times were optimised for each sample, based on acquired DLS correlograms (intensity autocorrelation in function of time). Processing was done using the Dynamics software, version 7.3.1.15 (Wyatt).

\subsubsection{Turbidimetry}

Optical density at incident wavelength of $600 \mathrm{~nm}$ (OD600) was taken as a measure for the turbidity of reconstituted samples, an additional criterion for the presence of aggregates exceeding the inherent size limit of SEC. Measurements were performed using a Spectramax M5 multi-detection microplate reader (Molecular Devices, Sunnyvale, California, U.S.).

\subsection{Supplementary analysis}

\subsubsection{Fourier transform infrared spectroscopy (FTIR)}

A Vertex 70 Fourier transform infra-red (FTIR) spectrometer (Bruker, Billerica, Massachusetts, U.S.) was used to assess conformational stability of the $\mathrm{mAb}$ in the dried state. Spectra were recorded (32 scans) in the 400 to $4000 \mathrm{~cm}^{1}$ range with a spectral resolution of $4 \mathrm{~cm}^{1}$. Data processing was done using version 7.5 of the OPUS software package (Bruker) and consisted of atmospheric compensation $\left(\mathrm{H}_{2} \mathrm{O}\right.$ and $\left.\mathrm{CO}_{2}\right)$ and vector normalisation. Interpretation of protein secondary structure stability was performed on the original spectrum following the aforementioned data processing and was based on the assessment of peak positions in the amide I band $\left(1700 \mathrm{~cm}^{(-1)}-1600\right.$ $\mathrm{cm}^{(-1)}$ ), being the most sensitive spectral region for secondary structure compositions in proteins (Yang et al. (2015)). 


\subsubsection{X-ray powder diffraction (XRPD)}

An automated Xpert PRO X-ray diffractometer (PANalytical, Almelo, The Netherlands), equipped with a $\mathrm{Cu}$ radiation source $(\lambda 1.5418 \AA$, voltage $45 \mathrm{kV}$, current $40 \mathrm{~mA}$ ), was used to determine powder crystallinity. Measurements were conducted in transmission mode using Kapton ${ }^{\circledR}$ (DuPont, Wilmington, Delaware) film. Samples were spun at a rate of 4 seconds per rotation with a counting time of 400 seconds per step and a step size of $0.0167^{\circ}$ in the range from $4^{\circ}$ to $40^{\circ} 2 \theta$. Data was analysed using version 1.7 of the Data Viewer software (PANalytical).

\subsubsection{Modulated differential scanning calorimetry (mDSC)}

Thermal Analysis of spray dried powders was performed with modulated differential scanning calorimetry (mDSC), using a Q2000 differential scanning calorimeter equipped with an RCS90 refrigerated cooling system (TA Instruments, Leatherhead, U.K.). Temperature calibration was performed using n-octadecane and indium standards, for enthalpy calibration only indium was used. Heat capacity calibration was performed using a sapphire standard, where total and reversing heat capacities were compared to their theoretical values at $106.85^{\circ} \mathrm{C}$. A temperature modulation of $0.50{ }^{\circ} \mathrm{C}$ every 80 seconds was applied over a linear heating rate of $1.00{ }^{\circ} \mathrm{C} / \mathrm{min}$. Samples were sealed in TA Instruments Standard Aluminium Hermetic Pans using TA Instruments Standard Aluminium Hermetic Lids and heated from -10.00 to $120.00{ }^{\circ} \mathrm{C}$, while the sample chamber was continuously purged with inert dry nitrogen gas at a flow rate of $50 \mathrm{ml} / \mathrm{min}$. Thermograms were analysed using the Universal Analysis software package version 4.5A (TA Instruments). Glass transition temperature regions are described by on- and offset temperatures of the transition and the midpoint, calculated at half height of the step change on the reversing heat flow signal curve.

\subsubsection{Scanning electron microscopy (SEM)}

The morphology of spray dried powder particles was characterised using a JSM-IT300 InTouchScope ${ }^{\circledR}$ scanning electron microscope combined with version 1.110 of the IT300 operation software (Jeol, Tokio, Japan). Spray dried powder samples were fixed onto cylindrical specimen mounts with double-sided carbon tape and a gold layer was subsequently applied using a Q150R ES Rotary-Pumped Sputter Coater/Carbon Coater (Quorum technologies, Lewes, U.K.). 


\section{Results}

\subsection{Formulation screening}

Data obtained for the different factor levels of the formulation screening design were used to fit regression models, containing nominal factors, for each of the responses. As the JMP software represents nominal variables by terms whose parameter estimates average to zero across all the levels, n-level nominal factors will be represented by n-1 indicator variables for processing. Therefore only n-1 parameter estimates could be obtained directly for the formulation screening since the parameter estimates were calculated by taking the difference between the average response corresponding to a certain level and the average response across all levels. Parameter estimates for the final factor level were then calculated separately based on the knowledge that parameter estimates across all levels of a nominal variable are constrained to sum to zero, i.e. the final term was calculated as the negative of the sum of the estimates across the other n-1 levels. This implies a dependency between the expanded parameter estimates (JMP Genomics 8 manual).

Spray dried powders had a residual water content ranging from $4.47 \%$ $\mathrm{m} / \mathrm{m}$ to $6.97 \% \mathrm{~m} / \mathrm{m}$. Neither plotting the different responses versus the residual water content, nor including it as an uncontrolled factor in the linear regression models showed a correlation between or a significant influence on the different responses. This was likely due to the narrow range of the residual water content values and the factor was consequently omitted from the different models.

The powders were reconstituted in triplicate at $100 \mathrm{mg} / \mathrm{ml}$, twice the $\mathrm{mAb}$ concentration in the feed solutions, and the expanded parameter estimates for the resulting model are shown in Figure A.1. Parameter estimates were significant at the 0.05 level for the surfactant factor and the single amino acid salt levels of L-arginineHCl and L-histidineHCl.

Protein stability after storage at $5{ }^{\circ} \mathrm{C}$ and after 4 weeks at $40{ }^{\circ} \mathrm{C}$ was characterised by means of three aggregation-focussed responses: the relative quantity of high Mw species as measured by SEC, the relative quantity of high Mw aggregates as measured by DLS and the turbidity of reconstituted samples, expressed as the OD600. For the spray dried formulations stored at $5{ }^{\circ} \mathrm{C}$, regression models could only be fitted for the high $\mathrm{Mw}$ species and high $\mathrm{Mw}$ aggregates responses (Figure A.2), while no models with normally distributed studentised residuals could be fitted for the protein stability responses measured for the formulations stored 4 weeks at $40{ }^{\circ} \mathrm{C}$. 
Figure A.3 summarises the raw data obtained for the different protein stability responses. The high $\mathrm{Mw}$ species response (Figure A.3a and Figure A.3b) clearly shows similar trends as those described by the model depicted in Figure A.2a and this at both time points. The high MW aggregates data (Figure A.3c and Figure A.3d) did not display patterns or trends similar to those present in the high $\mathrm{Mw}$ species (Figures A.3a and A.3b) or OD600 (Figures A.3e and A.3f) raw data. But similar trends as those described by the model depicted in Figure A.2b can be seen for the spray dried formulations stored at $5{ }^{\circ} \mathrm{C}$. The high variability that can be observed in the high $\mathrm{Mw}$ aggregates data can be attributed to the overall sensitivity of DLS as a technique to the presence of large particles and its related relatively low size cut-off. Nevertheless, Figure A.3c clearly shows an elevated presence of high Mw aggregates for the sub-population consisting of experiments 1 up to and including 8 (see Table A.2), being the formulations with sucrose as a sugar stabiliser in absence of a surfactant, compared to the sub-population consisting of experiments 9 up to and including 16 (see Table A.2), which had trehalose as a sugar stabiliser instead of sucrose. This notable difference between sucrose and trehalose formulations can also be discerned, albeit less clearly, for the formulations containing polysorbate 20 when comparing the number of measurements at the $0 \% \mathrm{~m} / \mathrm{m}$ high $\mathrm{Mw}$ aggregate level between the sub-population consisting of experiments 17 up to and including 24 (sucrose stabilised) and the sub-population consisting of experiments 25 up to and including 32 (trehalose stabilised) in Figure A.3c. It should also be noted that similar observations or trends can not be distinguished for the formulations stored 4 weeks at $40{ }^{\circ} \mathrm{C}$ (Figure A.3d). OD600 values were determined (Figure A.3e and Figure A.3f) as an orthogonal measure for larger insoluble particles present in the reconstituted samples. OD600 data data could not be fitted using linear regression due to the variability increasing with OD600 values, an increase which was likely caused by sedimentation of the larger particles present in the samples, once they exceeded a certain size. However, OD600 data displayed in Figures A.3e and A.3f clearly show an increase in turbidity for formulations lacking amino acid salts and an overall decrease in turbidity when polysorbate 20 is present. For the samples stored at $5{ }^{\circ} \mathrm{C}$ and 4 weeks at $40{ }^{\circ} \mathrm{C}$, even higher OD600 values could be observed for the samples lacking amino acid salts and a surfactant after storage at $40{ }^{\circ} \mathrm{C}$. 


\subsection{SD process parameter screening}

The SD process parameter screening design only contained continuous factors and responses, making a factor conversion like the one described for the formulation screening design (3.2.1) unnecessary for model fitting.

\subsubsection{Yield}

The yield in the collector, corrected for residual water content, was determined as a measure for process yield. The parameter estimates of the model fitted for the yield response are shown in Figure A.4. As can be observed from the model, inlet air temperature and feed rate were included as individual factors because of their involvement in significant secondary interactions, rather than being significant factors themselves.

\subsubsection{Powder characteristics}

The angle of repose was determined as a measure for powder flow. Parameter estimates for the model fitted for the angle of repose are shown in Figure A.5, with the inlet air temperature being the only non-significant factor in the model. Nevertheless, the inlet air temperature was included as a factor because of the interaction with the inlet air flow rate, which was statistically significant at the 0.05 level.

The residual water content data $(n=1)$ were fitted in a regression model which only contained one factor, the inlet air flow rate, which was significant at the 0.05 level. The model expression for the residual water content percentage (\%RWC) is given by equation 6 (coefficients are rounded to 2 decimal places). In the prediction expression, the inlet air flow rate is expressed as $1 /$ min and the parameter estimates \pm standard error as $\% \mathrm{~m} / \mathrm{m}$ per unit of inlet air flow rate, i.e. $1 / \mathrm{min}$. In addition the residual water content was plotted against the different responses and including as an uncontrolled factor in the linear regression models, but neither methods suggested a correlation between or a significant influence on the different responses.

$$
\% R W C=(11.44 \pm 0.23)-(0.57 \pm 0.24) \cdot\left(\frac{\text { Inl air flow }-320}{80}\right)
$$

To be able to fit a model with normally distributed studentised residuals for the reconstitution time $(\mathrm{n}=2)$, the first measurement of experiment 6 (see Table A.4), which was 17.1 minutes, had to be removed from the dataset. The removed value was identified as an outlier by both the Mahalanobis and 
jackknife distance tests and had the largest Cook's distance of the reconstitution time data set when a model was fitted with the outlier value included. The parameter estimates of the resulting model are summarised in Figure A.6.

Three variables describing the primary particle size distributions $(\mathrm{n}=3)$ could be fitted with normally distributed studentised residuals: the volume weighted mean $\mathrm{D}[4,3]$, span and uniformity; of which the parameter estimates are shown in Figure A.7. In order to fit the model for the volume weighted mean $\mathrm{D}[4,3]$ data displayed in Figure A.7a, the dataset had to be logarithmically transformed using the $\ln Z$ function, which calculates the natural logarithm of the values in the dataset with values equal to zero entered as zero. In the volume weighted mean $\mathrm{D}[4,3]$ model, three non-significant factors, the nozzle air flow rate, feed concentration and nozzle diameter, were included as they were part of interaction terms that were statistically significant at the 0.05 level. No transformations were needed to fit a model for the span data, of which the estimates are shown in Figure A.7b. All factors included in the span model were significant except for the nozzle diameter, which was included because it was part of a significant interaction. To be able to fit the uniformity parameter, the first of three measurements for experiment 18 ((see Table A.4), having a uniformity value of 1.264, had to be removed since this value was identified as an outlier by both the Mahalanobis and jackknife distance tests and had the largest Cook's distance for the model fitted with the outlier value included. $\mathrm{d}(0.10), \mathrm{d}(0.50), \mathrm{d}(0.90)$ and surface weighted mean $\mathrm{D}[3,2]$ measurements could not be fitted in a regression model with normally distributed studentised residuals. In this context it should be mentioned that the $512 \mu \mathrm{m}$ cut-off had to be applied to the measurement data of powders resulting from experiments 30, 31 and 33 (see Table A.4), as these displayed bimodal distributions. The secondary peaks of these distributions were most likely the result of large artefactual agglomerates present after ultrasonication and by definition not primary particles, thus deemed to be outside of the scope for this study. For the sake of completeness and scientific integrity, both filtered and unfiltered particle size distribution curves were added as supplementary information to this paper (See A.13).

In addition, particle size distributions of the powder fractions collected from the ProCepT Micro-Spray transport tube were measured to illustrate the influence of collection method and locations when characterising spray dried powders, i.e. the fraction obtained from the collector and cyclone compared to the fraction obtained from the transport tube, as depicted in 
Figure A.8.

All powders from the SD process parameter design (Table A.4) were analysed using scanning electron microscopy. SEM images representative for the entire sample set, are shown in Figure A.9. The selected spray dried powders were the result of different SD process parameters, but all yielded comparable values for the measured volume weighted mean $\mathrm{D}[4,3]$. As can be observed, the particles of the three samples display indentations or cavities, which are not uncommon for spray dried particles containing proteins, as previously reported by Ameri and Maa (2006). However, for some samples more spherical particles were observed, as depicted in Figure A.10. The prevalence of these large spherical particles appeared to be higher for samples spray dried using the $0.6 \mathrm{~mm}$ or $0.8 \mathrm{~mm}$ diameter nozzles, but they were still present in several powders produced using the $0.4 \mathrm{~mm}$ diameter nozzle. The cavities in the larger particles may or may not be filled with smaller particles. The composition, i.e. the ratio of small and larger particles which make up of the agglomerates, also differed between powders. Furthermore, different levels of "bridging" between the particles could be observed, with some agglomerates, seemingly merged together, as illustrated by the images given in Figure A.11.

XRPD and mDSC analysis (data not shown) confirmed that all samples were amorphous, regardless if they had been stored at $5{ }^{\circ} \mathrm{C}$ or at $40{ }^{\circ} \mathrm{C}$ for a period of 4 weeks. Comprehensive interpretation or modelling of the glass transition temperatures acquired with mDSC (data not shown), was not possible due to significant variability of the data which was tracked back to the sample preparation method.

\subsubsection{Protein stability}

Protein stability after storage at $5{ }^{\circ} \mathrm{C}$ and $40{ }^{\circ} \mathrm{C}$ during 4 weeks was characterised by the high $\mathrm{Mw}$ species, the high $\mathrm{Mw}$ aggregates and OD600 and the FTIR spectra (A.14). FTIR spectra, which were measured on the spray dried powders, showed no observable deviations in the amide bands or other indications of conformational changes. Parameter estimates for the models fitted for high Mw species and OD600 responses are shown in Figure A.12. In order to fit the model for the high $\mathrm{Mw}$ species response $(n=1)$ for the $5{ }^{\circ} \mathrm{C}$ condition (parameter estimates are displayed in Figure A.12a), the only outlier, the value measured for experiment 27 (see Table A.4), was removed since no model could be fitted which included the outlier to determine the Cook's distance. The resulting model did not include any significant main factors, only a statistically significant interaction. To fit the high Mw species 
model for the 4 weeks at $40{ }^{\circ} \mathrm{C}$ condition, the outlier with highest Cook's distance, being the value measured for experiment 2 (see Table A.4), was removed. The resulting model (parameter estimates are shown in Figure A.12b) only contained significant factors and interactions. In order to fit the OD600 data, datasets for both the $5{ }^{\circ} \mathrm{C}$ and the $40{ }^{\circ} \mathrm{C}$ storage conditions needed to be logarithmically transformed using the $\ln Z$ function. Parameter estimates for the model fitted for the $5{ }^{\circ} \mathrm{C}$ condition, shown in Figure A.12c, only contained one non-significant factor, the inlet air flow rate. The nozzle diameter was the only non-significant factor included in the model fitted for the $40{ }^{\circ} \mathrm{C}$ condition. Parameter estimates for the aforementioned model are shown in Figure A.12d. High Mw aggregate data (not shown) could not be fitted in a regression model with normally distributed studentised residuals and interpretation of the data did not allow us to draw any conclusions regarding factor effects on this response.

\section{Discussion}

\subsection{Formulation screening}

The current formulation screening study demonstrated the reconstitution time reducing and $\mathrm{mAb}$ stability enhancing properties of the hydrochloride salts of three basic amino acids, i.e. L-arginineHCl, L-histidine $\mathrm{HCl}$ and Llysine $\mathrm{HCl}$, at high $\mathrm{mAb}$ concentration. The average reconstitution time of the four formulations lacking amino acid hydrochloride salts was 28.5 minutes, with times $(n=3)$ ranging from 25.6 to 34.6 minutes; while the average reconstitution time was 17.3 minutes for the twenty-eight formulations containing one or more amino acid hydrochloride salts, with reconstitution times $(\mathrm{n}=3)$ ranging from 12.8 to 22.2 minutes. The observed effect on the reconstitution time (Figure A.1) could be explained by the effect of the amino acid hydrochloride salts on the mobility of the different formulation components during the drying step. For instance, viscosity lowering effects on albumin and IgG solutions, party attributed to shielding of electrostatic interactions between proteins, have been reported for the hydrochloride salts of all three basic amino acids (Inoue et al. (2014a,b); Tomar et al. (2015)). Differences in mobility due to altered viscosity could impact drying kinetics and subsequently affect particle size, morphology and the distribution of formulation components across the formed solid particles, potentially al-

tering their reconstitution profiles. For example, when a fraction of these highly soluble amino acid hydrochloride salts would become trapped at the 
droplet surface, between the network of large molecules, like the mAb and polysorbate 20, when the rate of water evaporation becomes higher than the diffusion rate in the droplet for these large molecules (Vehring (2008)). Even though the bulk of these small, highly soluble amino acid hydrochloride salts would reside more in the core of the particle due to their higher rate of diffusion and hydrophilic nature, a fraction of rapidly dissolving amino acid salts will still be present at the particle surface and could create additional surface area when going into solution, upon contact with the solvent, thus increasing the reconstitution rate. Regarding mAb stability, only small variations could be observed between the hydrochloride salts of basic amino acids or their combinations, despite differences in their amino acid side chain structures and physicochemical properties. Overall, the same trends could be observed between the stability responses of samples reconstituted after storage at $5{ }^{\circ} \mathrm{C}$ or $40{ }^{\circ} \mathrm{C}$ (Figure A.2 and Figure A.3), suggesting stabilising effects both during drying and in solid state (Figure A.3). Based on the acquired data, we could hypothesise that, for the studied conditions, the influence of the positive charge of the amino acid side chains at $\mathrm{pH} 5.0$ has a more pronounced effect on the protein stability than the differences in physicochemical properties of the amino acid side chains. This is in corroboration with the results of Forney-Stevens et al. (2016), who tested the stabilising effects of 15 amino acids on recombinant human serum albumin and $\alpha$-chymotrypsin during lyophilisation. Improved stability was reported for positively charged amino acid side chains with larger molar masses, explained by interactions with charged patches on the protein surface. The effect of the molar mass could explain why L-lysineHCl, having the smallest molecular weight amino acid side chain, appears to be less efficient in our screening. As the investigated $\mathrm{mAb}$ has its isoelectric point between $\mathrm{pH} 6.1$ and 6.3 , the influence and interactions with the negatively charged chloride ion should also be considered regarding protein stability during spray drying, storage and reconstitution as the effects of hydrochloric acid salt as a protein stabiliser, being more or less central in the Hofmeister series, have been extensively documented (Bye and Falconer (2013); Schneider et al. (2011); Platts and Falconer (2015); Goshima et al. (2016)). In this respect, it should be noted that our study design is limited since it does not contain a factor level with hydrochloric acid salt as the main stabiliser, hence not allowing us to distinguish the effects of the amino acid side chain from those of the hydrochloric acid component. In summary the current study provides a statistically substantiated comparison between the three hydrochloride salts of 
three basic amino acids with regard to relevant responses for spray drying $\mathrm{mAb}$ formulations for reconstitution, which to our knowledge has not been extensively researched, and stresses their added value when a disaccharide stabiliser is already present in the formulation.

Our results also confirm the protective influence of polysorbate 20 on the mAb during spray drying and reconstitution (Figure A.2 and Figure A.3). Polysorbate 20 reportedly positions itself preferentially at the air-liquid interface during drying, consequently decreasing structure perturbation of the protein when it comes into contact with the hydrophobic air-environment at the air-liquid interface (Lee et al. (2011); Wang et al. (2017). Little or no influence of polysorbate 20 could be observed on the storage stability of the powders stored at $40{ }^{\circ} \mathrm{C}$ during 4 weeks prior to reconstitution (A.3), which is in line with the findings of Wang et al. (2017), stating that at low concentrations, like the one used for this study, little or no direct interaction takes place between non-ionic surfactants and the protein. Taking into consideration the preferential presence of surfactants at the air-liquid interface during drying, higher polysorbate 20 concentrations can be expected to be present on the particle surface after drying. Considering its surface tension lowering properties, polysorbate 20 is therefore likely to serve as a wetting agent during reconstitution (Cao et al. (2013)), hence improving reconstitution time, as can be seen in Figure A.1. Thus, the present work confirmed the stabilising effects of and attributes reconstitution time enhancing properties to polysorbate 20 .

Previous experiments conducted within our research groups (data not shown) suggested the necessity of adding an additional stabiliser to an mAb formulation containing one or two amino acid stabilisers in order to ensure adequate solid state stability for storage at $40{ }^{\circ} \mathrm{C}$ during 4 weeks prior to reconstitution. The results of our comparative study between sucrose and trehalose (Figure A.2 and Figure A.3), both non-reducing disaccharides having been attributed protein stabilising qualities in literature, with trehalose generally accepted as the superior protein stabiliser (Lerbret et al. (2012); Cordone et al. (2015); Tonnis et al. (2015); Malferrari et al. (2016); Lipiäinen et al. (2016); Mensink et al. (2017)), revealed a statistically significant superior stabilising effect for trehalose compared to sucrose regarding the High $\mathrm{Mw}$ Aggregates response for samples reconstituted after storage at $5{ }^{\circ} \mathrm{C}$. This was clear in both the fitted regression model (Figure A.2b) and in the raw response data on which the regression model was based (Figure A.3c). This is in accordance with previous publications that state trehalose to generally 
be superior to sucrose concerning protein stabilisation and immobilisation, at least in glasses, due to the higher propensity of trehalose to form intermolecular hydrogen bonds compared to sucrose. A possible explanation for this difference in behaviour between the two homologous disaccharides is that sucrose forms two intramolecular hydrogen bonds between glucopyranosyl and fructofuranosyl in the crystalline form, which are likely still intact near the glass transition temperature in highly concentrated solutions (Malferrari et al. (2016)). Trehalose's higher propensity to form intermolecular hydrogen bonds strengthens the overall long-range protein-water-disaccharide hydrogen bond networks, which are essential in establishing a stable, homogeneous matrix to immobilise the protein in its native conformation both during the drying process and during subsequent storage (Cordone et al. (2015); Mensink et al. (2017)). When taking this into consideration, it would seem odd that a similar profile trend could not be observed for samples reconstituted after storage at $40^{\circ} \mathrm{C}$ during 4 weeks (Figure A.3d). This could be either due to a loss of matrix rigidity and associated higher mAb mobility during storage at $40{ }^{\circ} \mathrm{C}$, i.e. the difference of the $\mathrm{mAb}$ being anchored firmly or loosely to the matrix would be less significant if the matrix itself is no longer rigid enough to ensure sufficient immobilisation of the $\mathrm{mAb}$, or due to the aggregates becoming too large to still be observed using DLS, but too small or concentrated too low to be detected using turbidimetry. However, the variability on both DSC and DLS data does not allow us to unambiguously confirm the aforementioned hypothesis. The fact that only the DLS data displays the aforementioned trends is likely due to the nature of the aggregates measured. If the measured high $\mathrm{Mw}$ aggregates are native aggregates, these are unlikely to be observed using SEC, as the high $\mathrm{Mw}$ species detected using SEC are mostly non-native aggregates, i.e. aggregates of denatured proteins, which are known to be stabilised as dimers or other relatively small oligomers. Native aggregates, on the other hand, are aggregates of the protein in its native conformation, which are less likely to be stable as small oligomers and are consequently larger clusters of proteins, falling outside the detection range of SEC. If instead the aggregate fraction responsible for the detected differences between the sucrose and trehalose sub-populations would be non-native as well, it is possible that the oligomer state of the $\mathrm{mAb}$ was not maintained long enough to allow quantification with SEC, with the resulting large non-native aggregates being detected with DLS. That similar trends could not be observed in the turbidimetry data, is likely the consequence of aggregates either not being large enough or concentrated 
highly enough to create quantifiably different optical densities at $600 \mathrm{~nm}$. In addition, it should be noted that, despite the presence of a disaccharide, the amino acid salts still increased mAb stability during spray drying and reconstitution and during 4 weeks of storage at $40{ }^{\circ} \mathrm{C}$, suggesting it could be beneficial to routinely incorporate both excipient types in spray dried $\mathrm{mAb}$ formulations.

The different trends observed in case of the high Mw species (Figure A.3a and Figure A.3b) and OD600 (Figure A.3e and Figure A.3f) compared to the results obtained for the high $\mathrm{Mw}$ aggregates (Figure A.3c and Figure A.3d), also illustrated the need for orthogonal techniques when assessing protein aggregation as a measure for stability. Considering the sensitivity of DLS to the presence of large particles and relatively low cut-off, it was not the most suited technique for quantifying and comparing the larger Mw aggregate fractions, as the presence of large insoluble particles exceeding the aforementioned size cut-off increase variability, but it was able to reveal a difference in stabilising potential between sucrose and trehalose for samples stored at $5{ }^{\circ} \mathrm{C}$, that was not detected using SEC or turbidity measurements, once more confirming the necessity of using orthogonal techniques. Although an additional filtering step could remove the large insoluble particles responsible for the large variability, we did not implement this as it holds the inherent risk of shifting equilibria in the already diluted sample, thus resulting in an overall underestimation of the high $\mathrm{Mw}$ aggregates present in the original reconstituted sample. We also urge caution to, when using statistical tools, not forego the interpretation of the raw data where possible and combine this with relevant visual observations and the background and limitations of each technique to attain a more valid understanding of the models and data. As was the case for this screening study, samples void of any hydrochloride salts of a basic amino acid, showed a noticeable increase in turbidity, being a red flag marker for any protein solution. This prompted us to use the optical density at $600 \mathrm{~nm}$ as an additional technique. At $600 \mathrm{~nm}$ the $\mathrm{mAb}$ does not absorb light, so the decrease in light intensity at the detector will be due to scattering by large, (insoluble) particles, like aggregates. The OD600 is consequently correlated to the number, size and shape of these large particles and was found to be a good response for aggregate formation. An additional advantage of using the OD600 is that reconstituted samples could be measured as such, without the need for any dilution or filtration steps. A comprehensive review containing several orthogonal techniques for determining protein stability was written by Kamerzell et al. (2011). 


\subsection{SD process parameter screening}

The process parameter screening study produced a series of statistical models that, within the tested design space, identify and quantify the effects of spray drying process parameters on relevant powder and stability characteristics of $\mathrm{mAb}$ powders for reconstitution, leading to a better process understanding. Orthogonal techniques were used for quantifying both powder characteristics and descriptors for mAb stability. This study served as a first step in a process transfer from the Büchi B-290 Mini Spray Dryer to the ProCepT Micro-Spray. The ProCepT Micro-Spray enabled a higher level of process monitoring and its dimensions, i.e. a longer drying chamber, could make it a more straightforward model for pilot and production scale spray dryers with regard to particle engineering. It was however observed that the dimensions of the ProCepT Micro-Spray introduce the added risk of incorrectly estimating the particle size reproduced by the drying process. The proportional length of the transport tube is noticeable large, both compared to the size of the ProCepT Micro-Spray itself as to the connection between the drying chamber and cyclone of the Büchi B-290 Mini Spray Dryer or most industrial scale spray dryers. The influence of the transport tube dimensions was illustrated by comparing of primary particle size distribution values between the powder harvested from the cyclone and collector compared to the fraction of dry particles present in the transport tube, as shown in Figure A.8, which should be taken into account when trying to predict particle properties based on droplet droplet drying models (Mezhericher et al. (2010)).

The process yield as we defined it (the yield present in the collector after spray drying, corrected for residual water content) was judged to be the most representative as no manipulations are needed and it also serves as an indicator of sub-optimal processes if high quantities of powder are deposited on the cyclone wall. The model generated for the yield, displayed in Figure A.4, shows that the yield response is strongly, positively correlated with the inlet air flow rate and feed concentration, two factors which also display a positive interaction, suggesting a synergistic effect. We would also like to point out the significant cross-over interaction between the inlet air temperature and the feed rate, entailing that the effect of one factor will be positive or negative depending on the value of the other factor.

The model generated for the water content (Equation 6) only marked the inlet air flow rate as an influential factor. This can most likely be ascribed to the limited variation in residual water content between the spray dried powders, which ranged from $8.2 \% \mathrm{~m} / \mathrm{m}$ to $14.9 \% \mathrm{~m} / \mathrm{m}$, with the majority 
of powders having a residual water content between $10 \% \mathrm{~m} / \mathrm{m}$ and $12 \%$ $\mathrm{m} / \mathrm{m}$. Due to this limited response range, it would appear that only sufficient resolution was present to identity the most influential factor on the overall drying efficiency, being the inlet air flow rate, which is shown to be negatively correlated to the residual water content.

The factors exerting the greatest minimising effect on the angle of repose (Figure A.5), appear to be the nozzle diameter, inlet air flow rate and the feed concentration where attention should be paid to the interaction between inlet air flow rate and inlet air temperature. A lower feed rate could also aid in reducing the angle of repose, which is preferred when trying to obtain a free flowing powder, off course taking into account the significant interactions between the inlet air flow rate and the feed rate when determining an optimum. It should also be noted that the angle of repose can not directly be correlated to values obtained for the particle size distribution of the primary particles (Figure A.7), as these primary particles have been subjected to 30 seconds of ultrasonication in addition to at least 150 seconds of circulation at $2100 \mathrm{rpm}$, likely breaking up agglomerates that are present in the powder and effectively influence the angle of repose.

Only two factors were identified as significant for the reconstitution time of the amorphous powders, being the inlet air flow rate and the feed concentration. As a larger variability is inherent to the subjective nature of methods for determining reconstitution time (Werk et al. (2015)), the limited number of factors identified as significant could be a consequence of a lower overall resolution. Nevertheless, the two parameters that were identified as influential are in line with our expectations, as is the positive correlation between the reconstitution time and the inlet air flow rate. A higher inlet air flow rate could increase the drying rate relative to the diffusion rate within the droplet, consequently promoting the shell formation of the hollow particle and resulting in an overall larger particle, hence reducing the total surface area available for contact with the reconstitution solvent. The reconstitution time reducing influence of the feed concentration, on the other hand, is suspected to be a consequence of either differences in the distribution of formulation components within the particles or particle morphology, rather than particle size. This because, as reported by Vicente et al. (2013) and Vehring (2008), particle size increases substantially with the concentration of solids for dilute solutions $(\leq 5 \% \mathrm{~m} / \mathrm{m})$, which would logically yield a positive correlation between the reconstitution time and the feed concentration as an increase in particle size, or at least the size of the particles that make 
up strongly fused agglomerates would decrease the total surface area, thus increasing the reconstitution time. For more concentrated solutions, Vicente et al. (2013) also state that particle size will remain more or less unchanged, making it is less likely that the feed concentration would exert a statistically significant influence on the reconstitution time if this influence was caused by a difference in particle size.

Statistically significant models were generated for three particle size distribution descriptors of the primary particles obtained after 30 seconds of ultrasonication in addition to at least 150 seconds of circulation at $2100 \mathrm{rpm}$ (Figure A.7), a manipulation which would likely break up any agglomerates into their composing particles. However, no such assumptions can be made for the acquired laser diffraction data since the apparent strength of fusion for the agglomerates in the spray dried powders of this study noticeably differed between the powders, ranging from superficially (Figure A.9) to heavily fused together (Figure A.11). The differences in particle morphology ranging from almost perfect spheres (Figure A.10) to highly irregular particles with cavities sometimes containing smaller particles (Figure A.9), a comprehensive discussion of fundamental physical principles potentially underlying some of these particle properties was reported by Vicente et al. (2013) and Vehring (2008). This dissimilarity in particle morphology could potentially cause differences in how the light diffracts on their surfaces and combined with agglomerates being present that roughly have the same size as larger "mono"-particles (Figure A.9), we do not believe the particle size distribution models, although statistically significant, to be representative for any relevant powder properties. It would be therefore advisable to evaluate laser diffraction using a dry powder feeding cell or including additional techniques like the determination of the specific surface area via gas adsorption for similarly composed powders. Determining the specific surface area was not feasible for the present study as batch sizes were restricted and sample quantities needed were exceeding the gram range due to the non porous nature and therefore low total surface area of the produced powder particles. Contrary to the laser diffraction data, the acquired SEM images (Figure A.9, Figure A.10 and Figure A.11) were found to give a good representation of the powders, but a general downside of the technique, in respect of design of experiments, is the complexity of objectively expressing these observations as a continuous or categorical response, especially with powders as diversely composed as the ones obtained from the current study. In summary, this data serves as another example of the need for orthogonal techniques, combined with a 
sound interpretation of statistical models in regard to the physicochemical background of the data.

The mAb stability models displayed in Figure A.12 show that different spray drying process parameters are significant for the stability of samples stored at $5{ }^{\circ} \mathrm{C}$ (Figure A.12a and Figure A.12c) compared to those stored at $40{ }^{\circ} \mathrm{C}$ for a period of 4 weeks prior to reconstitution (Figure A.12b and Figure A.12d), confirming the presence of degradation processes in the solid state. These degradation processes are likely occurring at faster rates at the $40{ }^{\circ} \mathrm{C}$ storage condition, as increased temperatures will result in an increased molecular mobility, explaining the different models obtained for both storage conditions. For a more in depth discussion of protein solid state stability, the reader is referred to Cicerone et al. (2015).

Overall, the obtained particle characteristics models for the ProCepT Micro-Spray were distinctly different from those obtained with a Büchi B-290 Mini Spray Dryer by Kanojia et al. (2016); Grasmeijer et al. (2013) or Lebrun et al. (2012). For instance, the influence of the nozzle air flow rate was absent as a significant factor in our models for yield and powder characteristics, with the exception of the models obtained for the particle size distribution responses, but as mentioned above, these models should be interpreted with caution. Considering the obvious differences in spray dryer design between the ProCepT Micro-Spray and the Büchi B-290 Mini Spray Dryer, we believe it would be useful to compare the overall scalability of both lab scale spray dryers relative to spray dryers used on pilot or production scale. This could in turn help determine the scalability of the models generated with either lab scale spray dryer, as was reported by Gikanga et al. (2015), who compared a lab scale Anhydro MicraSpray 35 to a pilot-scale Anhydro MicraSpray150 (SPX Flow Technology Systems, Inc., Elkridge, MD).

\section{Conclusions}

The descriptive models generated for a model mAb during this study, can prove to be useful tools in improving the understanding of formulation and process parameter influences on the mAb stability and particle characteristics of powders for reconstitution. The models generated for the different responses can be combined and weighted at will to obtain powders with the desired properties, or at the very least help in determining which factors to vary and which factors to keep constant when designing future experiments. This work has also emphasised the importance of using orthogonal 
techniques when formulating biopharmaceuticals and keeping the physicochemical meaning of responses in mind when using statistical tools.

\section{Acknowledgements}

The authors would like to thank UCB Pharma for providing the equipment, materials and funding to make this study possible.

\section{References}

Ajmera, A., Scherließ, R., 2014. Stabilisation of proteins via mixtures of amino acids during spray drying. International Journal of Pharmaceutics 463 (1), 98-107.

Altman, N., Krzywinski, M., Apr. 2016. Points of significance: Analyzing outliers: influential or nuisance? Nat Meth 13 (4), 281-282.

Ameri, M., Maa, Y.-F., 2006. Spray drying of biopharmaceuticals: Stability and process considerations. Drying Technology 24 (6), 763-768.

Balcão, V. M., Vila, M. M., 2015. Structural and functional stabilization of protein entities: state-of-the-art. Advanced Drug Delivery Reviews 93, 25-41.

Barnett, G. V., Qi, W., Amin, S., Lewis, E. N., Roberts, C. J., 2015. Aggregate structure, morphology and the effect of aggregation mechanisms on viscosity at elevated protein concentrations. Biophysical Chemistry 207, $21-29$.

Bye, J. W., Falconer, R. J., 2013. Thermal stability of lysozyme as a function of ion concentration: A reappraisal of the relationship between the hofmeister series and protein stability. Protein Science 22 (11), 1563-1570.

Cao, W., Krishnan, S., Ricci, M. S., Shih, L.-Y., Liu, D., Gu, J. H., Jameel, F., 2013. Rational design of lyophilized high concentration protein formulations-mitigating the challenge of slow reconstitution with multidisciplinary strategies. European Journal of Pharmaceutics and Biopharmaceutics 85 (2), 287 - 293, sI: \{EJPB\} Freeze Drying (Invited only).

Cicerone, M. T., Douglas, J. F., 2012. [small beta]-relaxation governs protein stability in sugar-glass matrices. Soft Matter 8, 2983-2991. 
Cicerone, M. T., Pikal, M. J., Qian, K. K., 2015. Stabilization of proteins in solid form. Advanced Drug Delivery Reviews 93, 14-24.

Cordone, L., Cottone, G., Cupane, A., Emanuele, A., Giuffrida, S., Levantino, M., Sep. 2015. Proteins in saccharides matrices and the trehalose peculiarity: Biochemical and biophysical properties. Current Organic Chemistry 19 (17), 1684-1706.

den Engelsman, J., Garidel, P., Smulders, R., Koll, H., Smith, B., Bassarab, S., Seidl, A., Hainzl, O., Jiskoot, W., Sep. 2010. Strategies for the assessment of protein aggregates in pharmaceutical biotech product development. Pharmaceutical Research 28 (4), 920-933.

Forney-Stevens, K. M., Bogner, R. H., Pikal, M. J., 2016. Addition of amino acids to further stabilize lyophilized sucrose-based protein formulations: I. screening of 15 amino acids in two model proteins. Journal of Pharmaceutical Sciences 105 (2), 697-704.

Gikanga, B., Turok, R., Hui, A., Bowen, M., Stauch, O. B., Maa, Y.-F., 2015. Manufacturing of high-concentration monoclonal antibody formulations via spray drying - the road to manufacturing scale. PDA Journal of Pharmaceutical Science and Technology 69 (1), 59-73.

Goshima, H., Forney-Stevens, K. M., Liu, M., Qian, K. K., Tyagi, M., Cicerone, M. T., Pikal, M. J., 2016. Addition of monovalent electrolytes to improve storage stability of freeze-dried protein formulations. Journal of Pharmaceutical Sciences 105 (2), 530-541.

Grasmeijer, N., de Waard, H., Hinrichs, W. L. J., Frijlink, H. W., 2013. A user-friendly model for spray drying to aid pharmaceutical product development. PLoS ONE 8.

Inoue, N., Takai, E., Arakawa, T., Shiraki, K., 2014a. Arginine and lysine reduce the high viscosity of serum albumin solutions for pharmaceutical injection. Journal of Bioscience and Bioengineering 117 (5), 539 - 543.

Inoue, N., Takai, E., Arakawa, T., Shiraki, K., 2014b. Specific decrease in solution viscosity of antibodies by arginine for therapeutic formulations. Molecular Pharmaceutics 11 (6), 1889-1896, pMID: 24689736. 
Kamerzell, T. J., Esfandiary, R., Joshi, S. B., Middaugh, C. R., Volkin, D. B., 2011. Protein-excipient interactions: Mechanisms and biophysical characterization applied to protein formulation development. Advanced Drug Delivery Reviews 63 (13), 1118-1159.

Kanojia, G., Willems, G.-J., Frijlink, H. W., Kersten, G. F., Soema, P. C., Amorij, J.-P., 2016. A design of experiment approach to predict product and process parameters for a spray dried influenza vaccine. International Journal of Pharmaceutics 511 (2), 1098 - 1111.

Kinnunen, H. M., Mrsny, R. J., 2014. Improving the outcomes of biopharmaceutical delivery via the subcutaneous route by understanding the chemical, physical and physiological properties of the subcutaneous injection site. Journal of Controlled Release 182, $22-32$.

Lebrun, P., Krier, F., Mantanus, J., Grohganz, H., Yang, M., Rozet, E., Boulanger, B., Evrard, B., Rantanen, J., Hubert, P., 2012. Design space approach in the optimization of the spray-drying process. European Journal of Pharmaceutics and Biopharmaceutics 80 (1), 226 - 234.

Lee, H. J., McAuley, A., Schilke, K. F., McGuire, J., 2011. Molecular origins of surfactant-mediated stabilization of protein drugs. Advanced Drug Delivery Reviews 63 (13), 1160-1171.

Lerbret, A., Affouard, F., Hédoux, A., Krenzlin, S., Siepmann, J., BellissentFunel, M.-C., Descamps, M., 2012. How strongly does trehalose interact with lysozyme in the solid state? insights from molecular dynamics simulation and inelastic neutron scattering. The Journal of Physical Chemistry B 116 (36), 11103-11116, pMID: 22894179.

Lipiäinen, T., Peltoniemi, M., Räikkönen, H., Juppo, A., 2016. Spray-dried amorphous isomalt and melibiose, two potential protein-stabilizing excipients. International Journal of Pharmaceutics 510 (1), 311 - 322.

Mahler, H.-C., Friess, W., Grauschopf, U., Kiese, S., 2009. Protein aggregation: Pathways, induction factors and analysis. Journal of Pharmaceutical Sciences 98 (9), 2909-2934.

Malferrari, M., Savitsky, A., Lubitz, W., Mbius, K., Venturoli, G., 2016. Protein immobilization capabilities of sucrose and trehalose glasses: The effect 
of protein/sugar concentration unraveled by high-field epr. The Journal of Physical Chemistry Letters 7 (23), 4871-4877, pMID: 27934049.

Mensink, M. A., Frijlink, H. W., van der Voort Maarschalk, K., Hinrichs, W. L., 2017. How sugars protect proteins in the solid state and during drying (review): Mechanisms of stabilization in relation to stress conditions. European Journal of Pharmaceutics and Biopharmaceutics 114, 288 $-295$.

Mezhericher, M., Levy, A., Borde, I., 2010. Theoretical models of single droplet drying kinetics: A review. Drying Technology 28 (2), 278-293.

Moroz, E., Matoori, S., Leroux, J.-C., 2016. Oral delivery of macromolecular drugs: Where we are after almost 100 years of attempts. Advanced Drug Delivery Reviews 101, 108 - 121.

Ohtake, S., Kita, Y., Arakawa, T., 2011. Interactions of formulation excipients with proteins in solution and in the dried state. Advanced Drug Delivery Reviews 63 (13), 1053-1073.

Penny, K. I., 1996. Appropriate critical values when testing for a single multivariate outlier by using the mahalanobis distance. Journal of the Royal Statistical Society. Series C (Applied Statistics) 45 (1), 73-81.

Platts, L., Falconer, R. J., 2015. Controlling protein stability: Mechanisms revealed using formulations of arginine, glycine and guanidinium $\mathrm{HCl}$ with three globular proteins. International Journal of Pharmaceutics 486 (12), 131-135.

Roberts, C. J., 2014. Protein aggregation and its impact on product quality. Current Opinion in Biotechnology 30, 211-217.

Schneider, C. P., Shukla, D., Trout, B. L., 2011. Arginine and the hofmeister series: The role of ionion interactions in protein aggregation suppression. The Journal of Physical Chemistry B 115 (22), 7447-7458, pMID: 21568311.

Tomar, D. S., Kumar, S., Singh, S. K., Goswami, S., Li, L., Dec. 2015. Molecular basis of high viscosity in concentrated antibody solutions: Strategies for high concentration drug product development. mAbs 8 (2), 216-228. 
Tonnis, W. F., Mensink, M. A., de Jager, A., van der Voort Maarschalk, K., Frijlink, H. W., Hinrichs, W. L. J., 2015. Size and molecular flexibility of sugars determine the storage stability of freeze-dried proteins. Molecular Pharmaceutics 12 (3), 684-694.

Vehring, R., May 2008. Pharmaceutical particle engineering via spray drying. Pharmaceutical Research 25 (5), 999-1022.

Vicente, J., Pinto, J., Menezes, J., Gaspar, F., 2013. Fundamental analysis of particle formation in spray drying. Powder Technology 247, 1-7.

Wan, F., Møller, E. H., Yang, M., Jørgensen, L., 2012. Formulation technologies to overcome unfavorable properties of peptides and proteins for pulmonary delivery. Drug Discovery Today: Technologies 9 (2), e141 e146.

Wang, S., Wu, G., Zhang, X., Tian, Z., Zhang, N., Hu, T., Dai, W., Qian, F., 2017. Stabilizing two igg1 monoclonal antibodies by surfactants: Balance between aggregation prevention and structure perturbation. European Journal of Pharmaceutics and Biopharmaceutics 114, 263 - 277.

Wasserman, R. L., Melamed, I., Stein, M. R., Gupta, S., Puck, J., Engl, W., Leibl, H., McCoy, B., Empson, V. G., Gelmont, D., Schiff, R. I., 2012. Recombinant human hyaluronidase-facilitated subcutaneous infusion of human immunoglobulins for primary immunodeficiency. Journal of Allergy and Clinical Immunology 130 (4), 951 - 957.e11.

Werk, T., Huwyler, J., Hafner, M., Luemkemann, J., Mahler, H.-C., 2015. An impedance-based method to determine reconstitution time for freeze-dried pharmaceuticals. J. Pharm. Sci. 104 (9), 2948-2955.

Worku, Z., Aarts, J., Singh, A., Van den Mooter, G., 2014. Drug-polymer miscibility across a spray dryer: A case study of naproxen and miconazole solid dispersions. Molecular Pharmaceutics 11 (4), 1094-1101.

Yang, H., Yang, S., Kong, J., Dong, A., Yu, S., Mar. 2015. Obtaining information about protein secondary structures in aqueous solution using fourier transform ir spectroscopy. Nat. Protocols 10 (3), 382-396. 


\section{Appendix A. Supplementary information}

Appendix A.1. Particle size distribution curves

Appendix A.2. FTIR spectra 


\section{Figures}

Figure A.1: Expanded parameter estimates plot for the reconstitution time response of the spray dried formulations summarised in Table A.2. The model was calculated using the values measured $(\mathrm{n}=3)$ for samples stored at $5{ }^{\circ} \mathrm{C}$. Open bars identify non-significant parameters, while parameters that are statistically significant at the 0.05 level are identified by shaded bars. Error bars depict the estimated standard error for each of the estimated parameters. Intercept estimate $=18.69 \pm 0.45(\mathrm{SE})$ minutes.

(a)

(b)

Figure A.2: Expanded parameter estimates plot for the (a) high Mw species with the intercept estimate equalling $5.19 \pm 0.01$ (SE) \% Area and (b) high Mw aggregates response with the intercept estimate equalling $6.33 \pm 0.32(\mathrm{SE}) \% \mathrm{~m} / \mathrm{m}$ of the spray dried and reconstituted formulations summarised in Table A.2. The models were calculated using the values measured $(\mathrm{n}=3)$ for samples stored at $5{ }^{\circ} \mathrm{C}$. Open bars identify non-significant parameters, while parameters that are statistically significant at the 0.05 level are identified by shaded bars. Error bars depict the estimated standard error for each of the estimated parameters.

(a)

(e) (b)

Figure A.3: Stability responses measured for the formulations summarised in Table A.2 after spray drying, storage and reconstitution. (a) High $\mathrm{Mw}$ species values measured for samples stored at $5{ }^{\circ} \mathrm{C}$; (b) High $\mathrm{Mw}$ species values measured for samples stored at $40{ }^{\circ} \mathrm{C}$ during 4 weeks; (c) High Mw aggregates values measured for samples stored at $5{ }^{\circ} \mathrm{C}$; (d) High Mw aggregates values measured for samples stored at $40{ }^{\circ} \mathrm{C}$ during 4 weeks; (e) OD600 values measured for samples stored at $5{ }^{\circ} \mathrm{C}$; (f) OD600 values measured for samples stored at $40{ }^{\circ} \mathrm{C}$ during 4 weeks. 
Figure A.4: Parameter estimates plot of the model fitted for the yield response $(n=1)$ of the SD process parameter design (Table A.4). Open bars identify non-significant parameters, while parameters that are statistically significant at the 0.05 level are identified by shaded bars. Error bars depict the estimated standard error for each of the estimated parameters. Intercept estimate $=30.88 \pm 1.74(\mathrm{SE}) \%$.

Figure A.5: Parameter estimates plot of the model fitted for the angle of repose response of the SD process parameter design (Table A.4). The model was calculated using the values measured $(\mathrm{n}=3)$ for samples stored at $5{ }^{\circ} \mathrm{C}$. Open bars identify non-significant parameters, while parameters that are statistically significant at the 0.05 level are identified by shaded bars. Error bars depict the estimated standard error for each of the estimated parameters. Intercept estimate $=48.30 \pm 1.55(\mathrm{SE})^{\circ}$.

Figure A.6: Parameter estimates plot of the model fitted for the reconstitution time response of the SD process parameter design (Table A.4). The model was calculated using the values measured $(\mathrm{n}=2)$ for samples stored at $5{ }^{\circ} \mathrm{C}$. Open bars identify nonsignificant parameters, while parameters that are statistically significant at the 0.05 level are identified by shaded bars. Error bars depict the estimated standard error for each of the estimated parameters. Intercept estimate $=5.60 \pm 0.20(\mathrm{SE})$ minutes.

Figure A.7: Parameter estimates plot of the models fitted for the particle size distribution responses of the SD process parameter design (Table A.4). The model was calculated using the values measured $(\mathrm{n}=3)$ for samples stored at $5{ }^{\circ} \mathrm{C}$. Open bars identify nonsignificant parameters, while parameters that are statistically significant at the 0.05 level are identified by shaded bars. Error bars depict the estimated standard error for each of the estimated parameters. (a) Intercept estimate $=2.16 \pm 0.10$ (SE); (b) Intercept estimate $=2.27 \pm 0.17(\mathrm{SE})$; (c) Intercept estimate $=0.75 \pm 0.06(\mathrm{SE})$.

Figure A.8: Volume weighted mean $\mathrm{D}[4,3]$ of collector/cyclone and transport tube samples $(n=3)$ of the powders resulting from the SD process parameter design (Table A.4). Particle sizes for experiments $16,18,25,30,32,34$ and 35 could not be measured because the quantity of powder recovered from the transport tube was insufficient. Standard deviations are depicted by the error bars. 
Figure A.9: SEM images of selected powders from the SD process parameter design (Table A.4) with comparable values for their average $(n=3)$ volume weighted mean $\mathrm{D}[4,3]$. (a) \& (b) SEM images of the powder resulting from experiment 20 with average $(\mathrm{n}=3)$ volume weighted mean $\mathrm{D}[4,3]=7.235 \pm 0.010$ (SD) $\mu \mathrm{m}$; (c) \& (d) SEM images of the powder resulting from experiment 26 with average $(\mathrm{n}=3)$ volume weighted mean $\mathrm{D}[4,3]=7.701$ \pm 0.004 (SD) $\mu \mathrm{m}$; (e) \& (f) SEM images of the powder resulting from experiment 32 with average $(\mathrm{n}=3)$ volume weighted mean $\mathrm{D}[4,3]=7.052 \pm 0.393(\mathrm{SD}) \mu \mathrm{m}$.

\section{(a)}

(b)

Figure A.10: SEM images of spherical particles present in selected powders from the SD process parameter design (Table A.4). (a) SEM image of the powder resulting from experiment 01; (b) SEM image of the powder resulting from experiment 09.
(a)
(b)
(c)
(d)

Figure A.11: SEM images of strongly associated agglomerates present in selected powders from the SD process parameter design (Table A.4). (a) \& (b) SEM images of the powder resulting from experiment 11 at x1500 and x4500 magnification, respectively; (c) \& (d) SEM images of the powder resulting from experiment 28 at x1500 and x4500 magnification, respectively. 
Figure A.12: Parameter estimates plot of the models fitted for the high $\mathrm{Mw}$ species $(\mathrm{n}=1)$ and OD600 $(n=3)$ responses of the SD process parameter design (Table A.4). Open bars identify non-significant parameters, while parameters that are statistically significant at the 0.05 level are identified by shaded bars. Error bars depict the estimated standard error for each of the estimated parameters. (a) Parameter estimates plot of the high $\mathrm{Mw}$ species response of samples stored at $5{ }^{\circ} \mathrm{C}$. Intercept estimate $=6.68 \pm 0.03(\mathrm{SE}) \%$ Area; (b) Parameter estimates plot of the high $\mathrm{Mw}$ species response of samples stored at $40{ }^{\circ} \mathrm{C}$ during 4 weeks. Intercept estimate $=8.61 \pm 0.05$ (SE) \% Area; (c) Parameter estimates plot of the LnZ (OD600) response of samples stored at $5{ }^{\circ} \mathrm{C}$. Intercept estimate $=-3.90 \pm$ 0.13 (SE); (d) Parameter estimates plot of the LnZ (OD600) response of samples stored at $40{ }^{\circ} \mathrm{C}$ during 4 weeks. Intercept estimate $=-3.70 \pm 0.19(\mathrm{SE})$.

(a)

(b)

Figure A.13: Overlay of the particle size distribution curves of all powders collected from the SD process parameter design (Table A.4) and stored at $5{ }^{\circ} \mathrm{C}$, with numbers in the legend indicating the receptive experiment numbers. (a) The particle size distribution curves with the default $2000 \mu \mathrm{m}$ cut-off applied for all samples and (b) the particle size distribution curves with the $512 \mu \mathrm{m}$ cut-off applied for powders resulting from experiments 30,31 and 33 .

Figure A.14: Overlay of the FTIR spectra of all powders collected from the SD process parameter design (Table A.4) (a) after storage at $5{ }^{\circ} \mathrm{C}$ and (b) after storage at $40{ }^{\circ} \mathrm{C}$ during 4 weeks. 


\section{Tables}

Table A.1: Factors and factor levels used in the full factorial design

\begin{tabular}{lll}
\hline Factor & Factor level & Level value $^{\mathrm{a}}$ \\
\hline \multirow{4}{*}{ Amino Acid Salt } & No Amino Acid Salt & 0 \\
& HisHCl & 0.12 \\
& HrgHCl & 0.12 \\
& HisHCl \& ArgHCl \& LysHCl & 0.12 \\
& ArgHCl \& LysHCl & $0.06 \& 0.06$ \\
Sugar & HisHCl \& ArgHCl \& LysHCl & $0.06 \& 0.06$ \\
& Sucrose & $0.06 \& 0.06$ \\
Surfactant & Trehalose $0.04 \& 0.04$ \\
\cline { 2 - 3 } & No Surfactant & 0.05 \\
\hline
\end{tabular}

a Concentrations refer to the excipients' molar concentrations $(\mathrm{mol} / \mathrm{l})$ in the SD feed solution 
Table A.2: Full factorial design used in formulation screening

\begin{tabular}{|c|c|c|c|}
\hline $\operatorname{Exp} N^{\circ}$ & Amino Acid Salts & Sugar & Surfactant \\
\hline 1 & No amino acid salt & Sucrose & No surfactant \\
\hline 2 & $\mathrm{HisHCl}$ & Sucrose & No surfactant \\
\hline 3 & $\mathrm{ArgHCl}$ & Sucrose & No surfactant \\
\hline 4 & LysHCl & Sucrose & No surfactant \\
\hline 5 & $\mathrm{HisHCl} \& \mathrm{ArgHCl}$ & Sucrose & No surfactant \\
\hline 6 & HisHCl \& LysHCl & Sucrose & No surfactant \\
\hline 7 & ArgHCl \& LysHCl & Sucrose & No surfactant \\
\hline 8 & HisHCl \& ArgHCl \& LysHCl & Sucrose & No surfactant \\
\hline 9 & No amino acid salt & Trehalose & No surfactant \\
\hline 10 & $\mathrm{HisHCl}$ & Trehalose & No surfactant \\
\hline 11 & $\mathrm{ArgHCl}$ & Trehalose & No surfactant \\
\hline 12 & LysHCl & Trehalose & No surfactant \\
\hline 13 & HisHCl \& ArgHCl & Trehalose & No surfactant \\
\hline 14 & HisHCl \& LysHCl & Trehalose & No surfactant \\
\hline 15 & $\mathrm{ArgHCl} \&$ LysHCl & Trehalose & No surfactant \\
\hline 16 & HisHCl \& ArgHCl \& LysHCl & Trehalose & No surfactant \\
\hline 17 & No amino acid salt & Sucrose & Polysorbate 20 \\
\hline 18 & $\mathrm{HisHCl}$ & Sucrose & Polysorbate 20 \\
\hline 19 & $\mathrm{ArgHCl}$ & Sucrose & Polysorbate 20 \\
\hline 20 & LysHCl & Sucrose & Polysorbate 20 \\
\hline 21 & $\mathrm{HisHCl} \& \mathrm{ArgHCl}$ & Sucrose & Polysorbate 20 \\
\hline 22 & $\mathrm{HisHCl} \& \mathrm{LysHCl}$ & Sucrose & Polysorbate 20 \\
\hline 23 & ArgHCl \& LysHCl & Sucrose & Polysorbate 20 \\
\hline 24 & HisHCl \& ArgHCl \& LysHCl & Sucrose & Polysorbate 20 \\
\hline 25 & No amino acid salt & Trehalose & Polysorbate 20 \\
\hline 26 & $\mathrm{HisHCl}$ & Trehalose & Polysorbate 20 \\
\hline 27 & $\mathrm{ArgHCl}$ & Trehalose & Polysorbate 20 \\
\hline 28 & LysHCl & Trehalose & Polysorbate 20 \\
\hline 29 & $\mathrm{HisHCl} \& \mathrm{ArgHCl}$ & Trehalose & Polysorbate 20 \\
\hline 30 & HisHCl \& LysHCl & Trehalose & Polysorbate 20 \\
\hline 31 & $\mathrm{ArgHCl} \&$ LysHCl & Trehalose & Polysorbate 20 \\
\hline 32 & HisHCl \& ArgHCl \& LysHCl & Trehalose & Polysorbate 20 \\
\hline
\end{tabular}


Table A.3: Factors and factor levels used in the D-optimal design

\begin{tabular}{lcccc}
\hline Factor & Unit & $\begin{array}{c}\text { Lower } \\
\text { limit } \\
(-)\end{array}$ & $\begin{array}{c}\text { Center } \\
\text { point } \\
(0)\end{array}$ & $\begin{array}{c}\text { Upper } \\
\text { limit } \\
(+)\end{array}$ \\
\hline $\begin{array}{l}\text { Inlet air flow rate } \\
\text { (Inl air flow) }\end{array}$ & $\mathrm{l} / \mathrm{min}$ & 240 & 320 & 400 \\
$\begin{array}{l}\text { Inlet air temperature } \\
\text { (Inl air T) }\end{array}$ & ${ }^{\circ} \mathrm{C}$ & 120 & 135 & 150 \\
$\begin{array}{l}\text { Nozzle air flow rate } \\
\text { (Noz air flow) }\end{array}$ & $\mathrm{l} / \mathrm{min}$ & 12 & 13.5 & 15 \\
$\begin{array}{l}\text { Feed rate } \\
\text { (Feed rate) }\end{array}$ & $\mathrm{ml} / \mathrm{min}$ & 3 & 4.5 & 6 \\
$\begin{array}{l}\text { Feed concentration }{ }^{\text {a b }} \\
\text { (Feed conc) }\end{array}$ & $\mathrm{mg} / \mathrm{ml}$ & 20 & 60 & 100 \\
$\begin{array}{l}\text { Nozzle diameter } \\
\text { (Noz D) }\end{array}$ & $\mathrm{mm}$ & 0.4 & 0.6 & 0.8 \\
\hline
\end{tabular}

${ }^{a}$ Refers to the mAb concentration

${ }^{\mathrm{b}}$ Excipient to $\mathrm{mAb}$ ratios were identical for all feed solutions 
Table A.4: D-optimal design used for screening SD process parameters

\begin{tabular}{|c|c|c|c|c|c|c|}
\hline $\begin{array}{l}\text { Exp } \\
\mathrm{N}^{\circ}\end{array}$ & $\begin{array}{l}\text { Inlet air } \\
\text { flow rate }\end{array}$ & $\begin{array}{c}\text { Inlet air } \\
\text { tempera- } \\
\text { ture }\end{array}$ & $\begin{array}{l}\text { Nozzle air } \\
\text { flow rate }\end{array}$ & $\begin{array}{l}\text { Feed } \\
\text { rate }\end{array}$ & $\begin{array}{l}\text { Feed con- } \\
\text { centration }\end{array}$ & $\begin{array}{c}\text { Nozzle } \\
\text { diame- } \\
\text { ter }\end{array}$ \\
\hline 1 & - & + & - & + & + & 0 \\
\hline 2 & - & + & - & + & - & - \\
\hline 3 & - & - & - & + & - & + \\
\hline 4 & - & - & - & - & - & 0 \\
\hline 5 & - & - & + & + & - & 0 \\
\hline 6 & + & - & - & + & + & - \\
\hline 7 & - & - & - & - & + & + \\
\hline 8 & - & + & + & - & - & - \\
\hline 9 & + & + & - & - & + & 0 \\
\hline 10 & - & + & - & - & - & + \\
\hline 11 & + & - & + & + & + & 0 \\
\hline 12 & - & + & - & - & + & - \\
\hline 13 & + & + & + & - & - & 0 \\
\hline 14 & + & + & - & + & + & + \\
\hline 15 & + & - & + & - & + & - \\
\hline 16 & - & - & + & + & + & - \\
\hline 17 & - & + & + & + & + & + \\
\hline 18 & + & + & - & + & - & 0 \\
\hline 19 & + & + & - & - & - & - \\
\hline 20 & - & + & + & - & + & 0 \\
\hline 21 & + & + & + & - & + & + \\
\hline 22 & + & + & + & + & - & + \\
\hline 23 & - & - & + & - & - & + \\
\hline 24 & + & - & + & - & - & 0 \\
\hline 25 & + & - & + & + & + & + \\
\hline 26 & + & + & + & + & + & - \\
\hline 27 & - & - & - & + & + & 0 \\
\hline 28 & - & + & + & + & - & 0 \\
\hline 29 & + & - & + & + & - & - \\
\hline 30 & + & - & - & - & + & 0 \\
\hline 31 & - & - & + & - & + & 0 \\
\hline 32 & + & - & - & - & - & + \\
\hline 33 & - & - & - & - & - & - \\
\hline 34 & 0 & 0 & 0 & 0 & 0 & - \\
\hline 35 & 0 & 0 & 0 & 0 & 0 & - \\
\hline 36 & 0 & 0 & 0 & 0 & 0 & + \\
\hline
\end{tabular}

Values of the different factor levels are summarised in Table A.3 